\title{
ANÁLISIS DE ISLAS DE CALOR POR MEDIO DE IMÁGENES SATELITALES Y SISTEMAS DE INFORMACIÓN GEOGRÁFICOS EN EL ÁREA URBANA DE LA SABANA DE BOGOTÁ
}

\author{
Juan A. Aragón \\ Facultad de Ingeniería, \\ Programa de Ingeniería Ambiental, Universidad Libre \\ Cra. 70 \#53-40. 111071 Bogotá, Colombia \\ Juan-aragonm@unilibre.edu.co. \\ Esteban D. Rodríguez \\ Facultad de Ingeniería \\ Programa de Ingeniería Ambiental, Universidad Libre \\ Cra. 70 \#53. I-111071 Bogotá, Colombia \\ Esteband-rodriguezc@unilibre.edu.co \\ Gustavo A. Varon \\ Facultad de Ingeniería, \\ Programa de Ingeniería Ambiental, Universidad Libre \\ Cra. 70 \#53-40. 111071 Bogotá, Colombia \\ Gustavoa-varonq@unilibre.edu.co \\ Gabriel A. Sánchez \\ Facultad de Ingeniería, \\ Programa de Ingeniería Ambiental, Universidad Libre \\ Cra. 70 \#53-40. 111071 Bogotá, Colombia \\ Gabriela-sanchezp@unilibre.edu.co
}

\begin{abstract}
Resumen: En esta investigación, se denota la importancia de los sensores remotos en la delimitación de la Islas de calor urbano. Siendo estas causantes de los efectos nocivos en la salud humana, el favorecimiento de la dispersión de contaminantes y temperaturas extremas entre otros. Se utilizaron imágenes satelitales Landsat 8 del Servicio geológico de Es-
\end{abstract}


tados unidos (USGS), con un tamaño de escena total 170 x $183 \mathrm{Km}$, y datos meteorológicos de estaciones oficiales. Los datos relacionados con la temperatura superficial (LST) recopilados del satélite se compararon con los datos de temperatura seleccionados en estaciones meteorológicas de superficie, ubicadas en la sabana de Bogotá. Se recortó el área de estudio de la imagen satelital para procesar las bandas del espectro 10, 4 y 5 , usando un algoritmo de temperatura superficial para recolectar el mapeo satelital. Estos datos se analizaron estadísticamente como espacialmente considerando la distancia y la elevación entre las estaciones e interpolando con el método cokriging y el software ArcGIS 10.3®. Se detectaron espacialmente la geometría de las islas en zonas de alta urbanización, obteniendo la temperatura de píxeles y comparándolo con los datos de la estación de superficie. Los resultados muestran diferencias entre la temperatura en zonas urbanas comúnmente con más vegetación y los dos métodos utilizados para este estudio.

Palabras clave: Isla de Calor, Landsat 8, Sensores remotos, Temperatura, Sabana de Bogotá.

Abstract: In this research, the importance of remote sensors in the delimitation of the urban heat islands is denoted. These being the cause of harmful effects on human health, favouring the dispersion of pollutants and extreme temperatures, among others. Landsat 8 satellite images from the United States Geological Service (USGS) were used, with a total scene size $170 \times 183 \mathrm{~km}$, and meteorological data from official stations. The data related to surface temperature (LST) collected from the satellite were compared with the selected temperature data in surface meteorological stations, located in the Bogota Sabena. The study area was cropped from the satellite image to process spectrum bands 10, 4 and 5, using a surface temperature algorithm to collect the satellite mapping. These data were statistically and spatially analysed considering the distance and elevation between the stations and interpolating with the cokriging method and ArcGIS $10.3{ }^{\circledR}$ software. The geometry of the islands was spatially detected in areas of high urbanization, obtaining the pixel temperature and comparing it with the data from the surface station, finding differences between the temperature in urban areas commonly with more vegetation and the two methods used for this study.

Keywords: Heat Island, Landsat 8, Remote Sensors, Temperature, Bogota savanna. 


\section{Introducción}

La actividad humana ha tenido un gran aumento con el pasar de los años, esto conlleva a la aparición de impactos antropogénicos que han llegado afectar tanto la salud del hombre como en el medio ambiente (Taha, 1997; Jauregui y Romales, 1996), uno de estos impactos, se conoce como Isla de Calor Urbano o UHI por sus siglas en inglés (Urban Heat Island). Los estudios sobre la Isla de calor urbano tienen sus inicios gracias a (Howard, 1833), el cual encontró una diferencia de temperatura entre la metrópolis inglesa con sus alrededores Greenwich de hasta $0.83^{\circ} \mathrm{C}$ en 1817 . No fue hasta 1962 que el investigador (Chandler, 1962), guiado por los eventos de "La gran niebla" de 1952 en Londres trajo un deterioro a la salud de aproximadamente 4000 víctimas (Davis, 2003), en algunos casos provocando la muerte. Este investigador, buscó otros fenómenos que pudieran llegar a ser igual o peor de nocivos para el ser humano, y en su investigación encontró picos de temperatura de hasta $14.6^{\circ} \mathrm{C}$, en los distritos centrales y $14.22^{\circ} \mathrm{C}$ en los suburbios con una temperatura que se asemeja la forma de isla en un área de 8.046 km (Chandler, 1964). A esto lo refuerzan estudios posteriores (Oke, 1973; Maxwell, 1967; Arnfield, 2003; Rizwan, Dennis y Liu, 2008; Garnett, 1967) a esto lo refuerzan estudios posteriores donde se expone el tamaño de la isla y la base energética que la conforma. Uno de estos estudios (Oke y Maxwell, 1967) descubrió que en las horas de la tarde las islas de calor tenían su mayor crecimiento por la inversión térmica que se presenta al momento de que los objetos empiezan a desprender calor al entorno. A partir de lo anterior, se entiende la isla de calor como una acumulación de calor en un punto rodeado de espacios más fríos creando una forma geométrica que a su vez tiene semejanza a una isla (Gartland, 2008; Thomas et al., 2014; Vide, Sarricolea, y Moreno, 2015).

La detección de las UHI va desde tomas de datos con sensores remotos como estaciones meteorológicas o herramientas que permiten registros de temperatura de manera terrestre hasta la obtención de datos mediante imágenes satelitales. hoy en día el uso de imágenes satelitales para la búsqueda y modelación del fenómeno UHI ha ido tomando más fuerza con el tiempo (Matson et al., 1978; Lo, Quattrochi y Luvall, 1997). En ese sentido, el uso de las imágenes de sensores remotos permite calcular la temperatura superficial terrestre o LST por sus siglas en inglés (Land Surface Temperature). Por ejemplo, Imhoff y otros autores en el 2010 logran identificar y detectar el aumento de la temperatura con el uso de la herramienta satelital en 38 estados de Estados Unidos, encontraron una diferencia de $2.2^{\circ} \mathrm{C}$ entre las zonas con cubierta vegetal a las ciudades (Imhoff et al., 2010; Senanayake, Welivitiya y Nadeeka, 2013). Según los resultados del trabajo anteriormente mencionado, la perdida de vegetación y el uso de materiales de construcción cuya composición presentan un bajo índice de reflectancia o albedo trae con estas diferencias de temperatura en algunos casos de $3^{\circ} \mathrm{C}$ (Estoque, Murayama y Myint, 2017), al mismo tiempo las áreas urbanas acumulan radiación proveniente del sol en forma de calor, así llegando a detectar la urbe con un aumento de temperatura (Rizwan, Dennis y Liu, 2008; Weng, 2003). 
Es importante mencionar que aun cuando estas islas de calor suelen presentarse en la fase diurna de las 24 horas del día, también en la noche pueden llegar a formarse a causa de la acumulación de calor presente en los diferentes materiales de construcción urbano, por la capacidad calorífica con la que estos cuentan que a su vez se desprende en la noche formando la geometría de las islas (Oke, Johnson y Steyn, 1991; Xiao, Hong, Ping y Zhi, 2006).

En cuanto a la detección de la isla de calor con sensores remotos, se destaca que en España (Pérez, García y Guerra, 2003) con los satélites GOES y Landsat lograron detectar la geometría de islas de manera similar a como sería con estaciones meteorológicas recalcando una ventaja de las imágenes satelitales por la cantidad de datos sobre las estaciones que cuentan con menos datos. Por otro lado, en Centroamérica, en TampicoMéxico (Haro, 2017), analizó el efecto que tienen las construcciones como obstáculos además de la topografía y morfología para la radicación de onda larga del sol en la formación geométrica de la isla de calor (Pérez, 2014; Zhou, Rybski y Kropp, 2017).

También en Colombia existen estos tipos de estudios, por ejemplo J.D. Pabón junto a otros autores (Pabón et al., 1998), fueron los pioneros en detectar estas islas en la Sabana de Bogotá donde la diferencia de temperatura entre la periferia y la zona urbana alcanza $3^{\circ} \mathrm{C}$. En 2013, Narváez y Ruiz, por medio de las estaciones meteorológicas, midieron variables como temperatura, precipitación, humedad relativa entre otras, y fue así como con estos indicadores encontraron la formación del fenómeno UHI principalmente en tres localidades: Kennedy, Engativá y Suba (Narváez y Ruiz, 2013; Gómez y Castañeda, 2013). De igual manera, otro estudio realizado en la ciudad encontró, en la localidad de Kennedy (Figueroa y Fiquitiva, 2017), que se puede llegar a identificar 3 tipos de islas de calor: Isla de calor de tipo capa dosel, Isla límite e Isla superficial, encontrando similitud con lo propuesto por (Oke, 1976).

De igual modo en Medellín (Soto, 2019) se detectó con imágenes satelitales que la UHI tiene una mayor intensidad, alcanzando los $4.81^{\circ} \mathrm{C}$ de diferencia. En esta misma región en el Valle de Aburra (Osorio, 2017), se encontró como el ciclo anual de la isla de calor está sincronizada con el ciclo anual de la temperatura y además hay fuertes indicios que identifica que la temperatura está disminuyendo en las épocas cálidas y aumentando en las temporadas húmedas, en los últimos 17 años (2000-2017).

El 2\% de la superficie terrestre está ocupada por las ciudades, y el 75\% del recurso energético es consumido por sus habitantes (Gago et al., 2013), lo que hace importante tener las herramientas necesarias para identificar que alcance tiene este fenómeno a causa de la expansión urbanística. Bogotá presenta una pérdida de vegetación a un ritmo acelerado debido a su crecimiento poblacional, creando la necesidad de conocer que efectos tiene la pérdida de vegetación ya que entre menos espacio público tenga cada habitante, su calidad de vida se puede ver afectada. Por ejemplo, en Bogotá solo el 2.58\% son zonas públicas según un estudio realizado con imágenes satelitales (Muños y Naranjo, 2015). Es fundamental disponer de sensores remotos como los satélites 
y estaciones meteorológicas como herramientas para identificar que nuevos fenómenos o variables se producen a partir de la expansión urbanística como la UHI. El principal objetivo de este trabajo es delimitar la geometría por medio de los sistemas de información geográficas y métodos estadísticos, así como, comparar los resultados obtenido con las imágenes satelitales y estaciones meteorológicas en los periodos 2015 y 2018.

\section{Materiales y Métodos}

El área de estudio se encuentra cercana a los límites de la Sabana de Bogotá y está delimitado entre los $4^{\circ} 34^{\prime}-4^{\circ} 54^{\prime}$ de latitud norte y los $73^{\circ} 52^{\prime}-74^{\circ} 18^{\prime}$ de longitud oeste, abarca de manera parcial o total los siguientes municipios: El Rosal, Subachoque, Tenjo, Tabio, Cota, Chía, Cajicá y Sopó al norte, Guasca, La Calera y Choachí al este, Facatativá, Bojacá, Madrid, Mosquera y Funza al oeste, y por ultimo Soacha hacia el sur del estudio, como se puede apreciar en la (Figura 1). Hacia el centro del área de estudio se localiza la ciudad de Bogotá, que tiene una temperatura que varía entre los 12 a $15^{\circ} \mathrm{C}$ (Perez, 2000), y se destaca que la mayor parte del tiempo se encuentra nublada, en un 70\% de las veces (Leyva, 2001; Morris, Simmonds y Plummer, 2001). El área de estudio se delimito basado en las estaciones meteorológicas según su malla de datos.

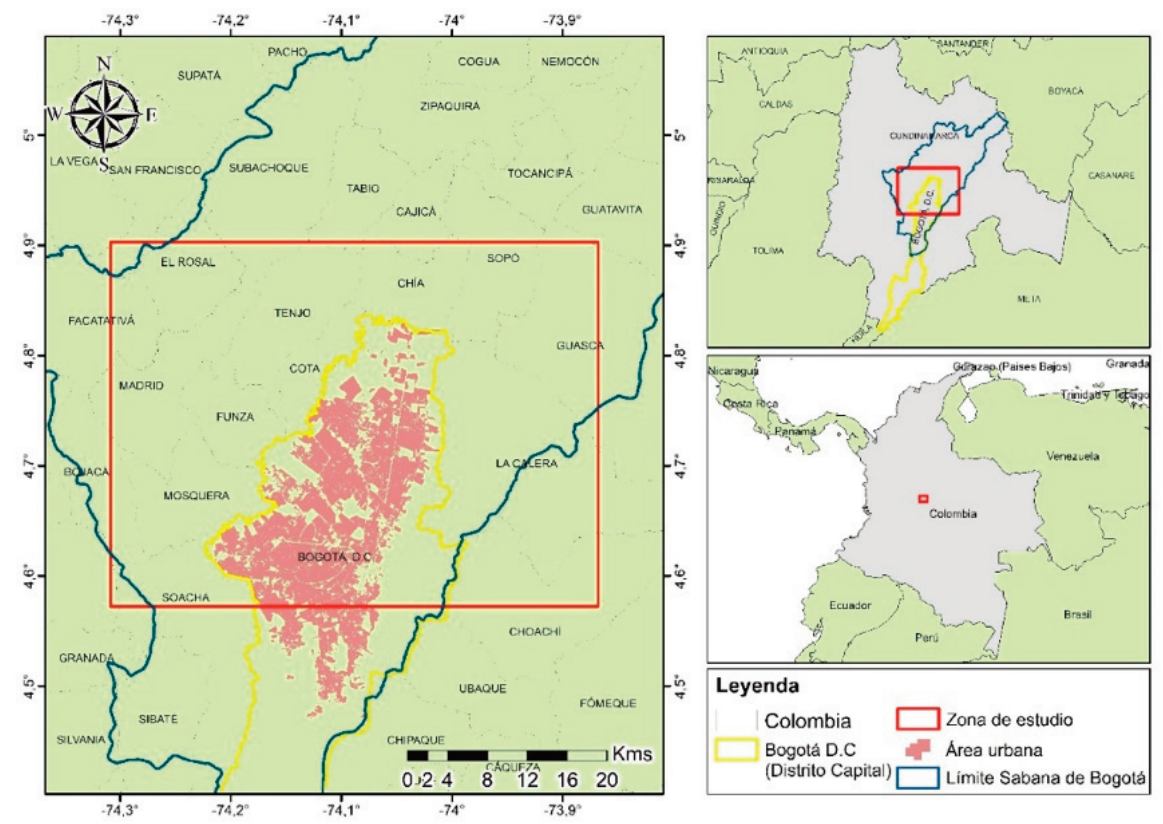

Figura 1. Localización del área de estudio.

Fuente: Elaboración propia a partir de las capas del Marco Geoestadístico Nacional (MGN). 
Como primer paso en este estudio se utilizaron imágenes satelitales Landsat 8 obtenidas desde el servidor de imágenes Earth Explorer (USGS, 2018) perteneciente al Servicio Geológico de los Estados Unidos o USGS por sus siglas en inglés (United States Geological Survey). En esta plataforma las imágenes seleccionadas corresponden a la colección 1 nivel 1 y se aplicó el criterio de nubosidad inferior al 26\%. Estas imágenes son captadas gracias a dos sensores: El Operational Land Imager (OLI) que captura las bandas 1- 9 y el sensor infrarrojo térmico (TIRS) que captura las bandas 10 y 11, con una resolución espacial de 30 y 100 metros respectivamente, el tamaño aproximado de la escena, el área total de la imagen es de 170x183 Km (USGS, 2018).

Para el tratamiento de las imágenes satelitales se procesó con el sistema de información geográfico ArcGIS 10.3 y su herramienta Calculadora Ráster para interactuar con las bandas de la imagen satelital, de acuerdo con las metodologías de (Ariza, 2013) y el procesamiento de la (Figura 2).

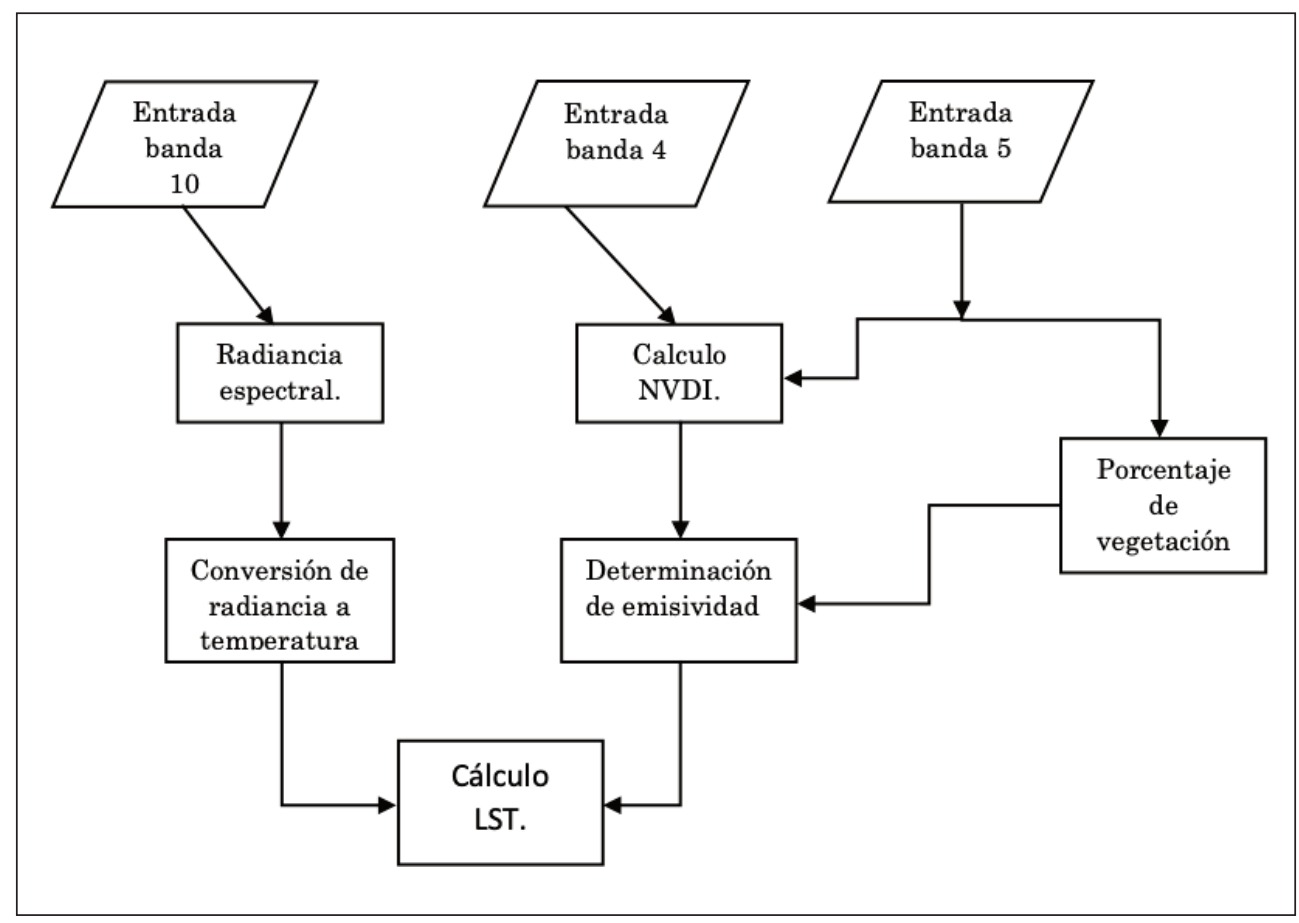

Figura 2. Procesamiento de la imagen satelital.

Fuente: Adaptado de (Avdan y Jovanovska, 2015). 
Este algoritmo permite calcular la Temperatura de superficie terrestre y corregirla teniendo en cuenta la proporción de vegetación que se halla en el área de estudio como se expresa en (1).

$$
T_{S}=\left(\frac{B T}{\left\{1+\left[\left(\mu * \frac{B T}{\rho}\right) \ln \varepsilon_{\mu}\right]\right\}}-10\right)
$$

Donde $\mathrm{T}_{\mathrm{S}}$ es la temperatura superficial (LST), BT es la temperatura de brillo, $\mu$ es la longitud de onda de radiancia emitida, $\varepsilon \mu$ es la emisividad, y $\rho=\mathrm{h}(\mathrm{c} / \sigma)=1.438 \times 10^{-2} \mathrm{~m} \mathrm{~K}$ donde $\sigma$ es la constante de Boltzmann, es la constante de Planck y c es la velocidad de la luz. En cuanto a las clases se determinaron 5, en función de la temperatura media anual según (IDEAM, 2002) y se generaron intervalos semejantes de temperatura dentro del rango de mayor representación.

En la segunda etapa de este trabajo se obtuvieron los datos de temperatura del aire, solicitando la información de las estaciones meteorológicas que se localizan en el área de estudio a la Red de monitoreo de calidad del aire de Bogotá (RMCAB) y al Instituto de hidrología, meteorología y estudios ambientales (IDEAM). Para ambas entidades los periodos solicitados fueron los correspondientes a las imágenes satelitales entre enero y febrero del 2015 y entre marzo y diciembre del 2018. En el caso de RMCAB los datos proporcionados son promedios horarios de temperatura de los días solicitados para el estudio, y los datos de temperatura por parte del IDEAM son promedios diarios de los días solicitados. Ya que no todas las estaciones contaban con la totalidad de los datos necesarios, se vio la necesidad de completar los datos faltantes, al respecto se menciona que se pueden usar varios métodos estadísticos como el Coeficiente de correlación de Pearson, Coeficiente de correlación de Rho Sperman, Coeficiente de correlación basados en, regresión estadística entre otros (Rodríguez et al., 2006; Wilks, 2006).

Para este estudio se utilizó el coeficiente de correlación de Pearson en las estaciones que tenían ausencia de datos, principalmente las estaciones de la RMCAB estos datos complementados representan el $0.38 \%$ frente a los datos originales de las estaciones meteorológicas superficiales. Una vez se obtuvieron los datos de temperatura del aire de ambas bases de datos, se elaboraron los mapas de temperatura con una malla de $48.9 \mathrm{Km}$ x $36.5 \mathrm{Km}$. Para ello se usó la herramienta análisis geoestadístico implementando coKriging ordinario con un modelo de semivariograma esférico, siendo una herramienta usada para predecir el comportamiento de una variable en el espacio y la correlación que existe entre datos (Henao, 2015). La geoestadística con los sistemas de información geográficas (SIG) han sido de gran utilidad para el análisis en la distribución espacial de variables en este caso la temperatura (García, 2004). 
Por otro lado, las estaciones meteorológicas del IDEAM y RMCAB, se representaron en un mapa lo que permitió tener la dimensión espacial superficial del estudio (Figura 3). Las estaciones cubren un área menor respecto a las imágenes satelitales, esto a causa de la ausencia de estaciones meteorológicas.

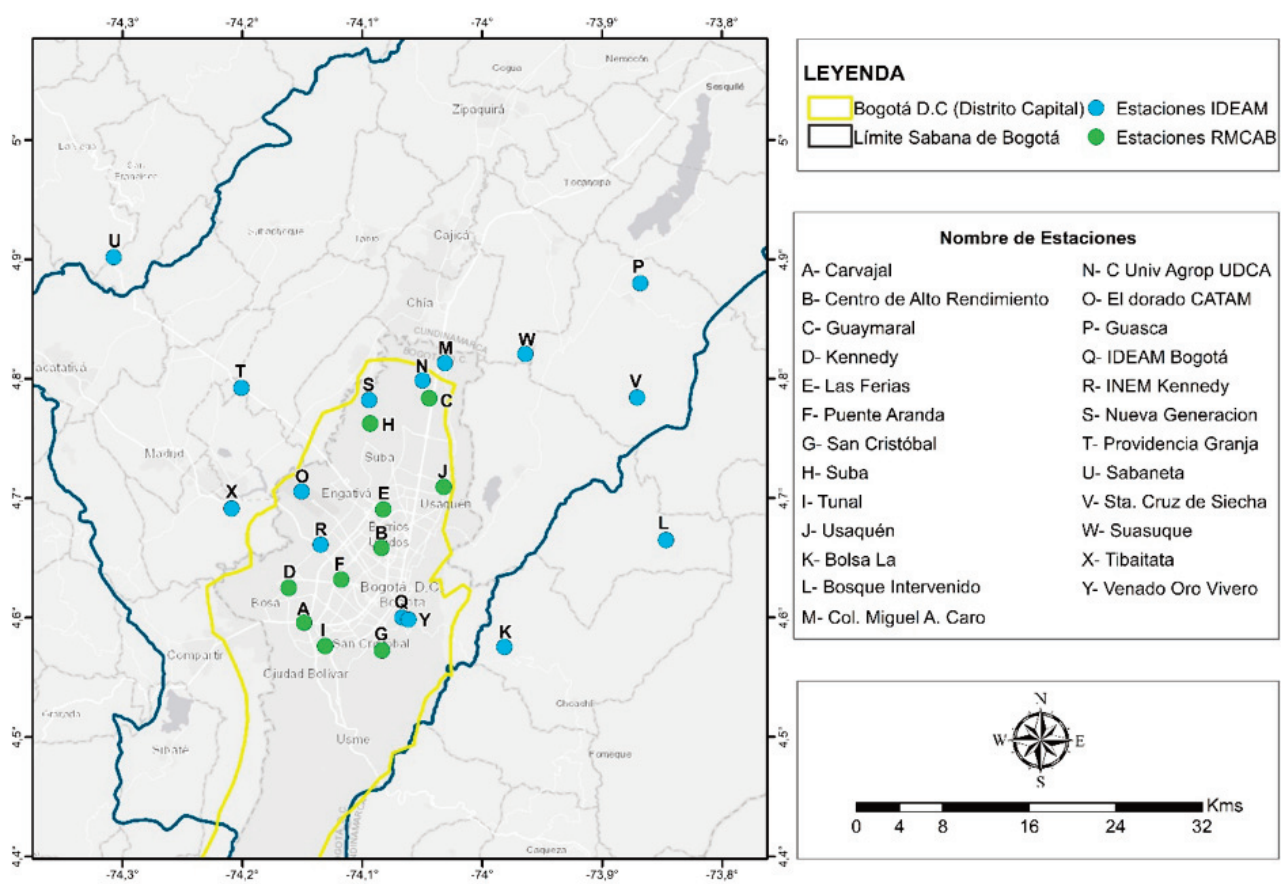

Figura 3. Ubicación de estaciones meteorológicas en el área de estudio.

Fuente: Elaboración propia.

Una vez suministrados los datos de las estaciones, se homogenizaron y se consolidaron en el mismo formato para el análisis estadístico en una hoja de cálculo electrónica, haciendo un control de datos se verificó primero que los datos no sobrepasaran los máximos y mínimos registrados en la ciudad de Bogotá los cuales equivalen a $25^{\circ} \mathrm{C}$ y $0{ }^{\circ} \mathrm{C}$ respectivamente, siendo en total 1.011 datos, de manera que todos los datos fueron validados.

Y debido a la morfología de Bogotá, donde cada estación está ubicada en diferentes altitudes Tabla 1, es un dato que se debe tener en cuenta ya que las características del área de estudio influyen en el análisis (Pérez, 2014; Zhou, Rybski y Kropp, 2017). 
Tabla 1. Ubicación Geográfica de las Estaciones Meteorológicas

\begin{tabular}{|c|c|c|c|c|}
\hline Estación & Letra & Latitud $\left({ }^{\circ}\right)$ & Longitud $\left({ }^{\circ}\right)$ & Altitud $(m)$ \\
\hline Carvajal & A & 4,596 & $-74,149$ & 2.563 \\
\hline Centro de Alto Rendimiento & $\mathrm{B}$ & 4,658 & $-74,084$ & 2.548 \\
\hline Guaymaral & $\mathrm{C}$ & 4,784 & $-74,044$ & 2.580 \\
\hline Kennedy & $\mathrm{D}$ & 4,625 & $-74,161$ & 2.580 \\
\hline Las Ferias & $\mathrm{E}$ & 4,691 & $-74,083$ & 2.552 \\
\hline Puente Aranda & $\mathrm{F}$ & 4,632 & $-74,118$ & 2.590 \\
\hline San Cristóbal & G & 4,573 & $-74,084$ & 2.688 \\
\hline Suba & $\mathrm{H}$ & 4,763 & $-74,093$ & 2.571 \\
\hline Tunal & $\mathrm{I}$ & 4,576 & $-74,131$ & 2.589 \\
\hline Usaquén & $\mathrm{J}$ & 4,709 & $-74,032$ & 2.570 \\
\hline Bolsa La & $\mathrm{K}$ & 4,575 & $-73,981$ & 3.195 \\
\hline Col_Miguel_A_Caro & $\mathrm{L}$ & 4,813 & $-74,031$ & 2.700 \\
\hline C_Univ_Agrop_UDCA & $\mathrm{N}$ & 4,799 & $-74,050$ & 2.570 \\
\hline Eldorado CATAM & $\mathrm{O}$ & 4,706 & $-74,151$ & 2.547 \\
\hline Guasca & $\mathrm{P}$ & 4,880 & $-73,868$ & 2.750 \\
\hline IDEAM Bogota & Q & 4,600 & $-74,067$ & 2.646 \\
\hline INEM Kennedy & $\mathrm{R}$ & 4,661 & $-74,135$ & 2.580 \\
\hline Nueva Generación & S & 4,782 & $-74,094$ & 2.590 \\
\hline Providencia Granja & $\mathrm{T}$ & 4,792 & $-74,201$ & 2.560 \\
\hline Sabaneta & $\mathrm{U}$ & 4,902 & $-74,307$ & 2.475 \\
\hline Santa Cruz De Siecha & $\mathrm{V}$ & 4,784 & $-73,871$ & 3.100 \\
\hline Suasuque & W & 4,821 & $-73,964$ & 2.650 \\
\hline Tibaitata & $\mathrm{X}$ & 4,691 & $-74,209$ & 2.543 \\
\hline Venado Oro Vivero & $\mathrm{Y}$ & 4,598 & $-74,062$ & 2.725 \\
\hline
\end{tabular}

Fuente: Elaboración propia, tomado de (IDEAM, 2018; RMCAB, 2018).

En la tercera etapa del estudio, se realizó la comparación de temperaturas entre los mapas elaborados a partir de las imágenes satelitales y los mapas hechos a partir de las estaciones meteorológicas. Para ello se tomaron los valores de temperatura de las 
estaciones meteorológicas que se obtuvieron del IDEAM y de la RMCAB, y se restaron a los valores de temperatura del píxel donde se encuentra la estación meteorológica en las imágenes satelitales, con el fin de calcular la diferencia de temperaturas presentada en los dos métodos utilizados.

\section{Resultados y Discusión}

De las imágenes satelitales que están disponibles en la página del Servicio Geológico de Estados Unidos, fueran seleccionadas cuatro imágenes conforme lo indicado en la Tabla 2, para ello se descartaron imágenes que no cumplían con el criterio de baja nubosidad menor al $26 \%$ y que esta nubosidad no estuviese presente sobre el área de estudio, considerando que entre mayor sea este porcentaje, menor será la confiabilidad en la detección de la isla de calor (Morris et al., 2001).

Tabla 2. Imágenes Seleccionadas

\begin{tabular}{|l|c|c|c|}
\hline Sensor & Año & Fecha de Captura & Hora (UTC-5) \\
\hline Landsat 8 & 2015 & 4 de enero & $10: 12: 33$ \\
\hline Landsat 8 & 2015 & 21 de febrero & $10: 12: 47$ \\
\hline Landsat 8 & 2018 & 17 de marzo & $10: 12: 17$ \\
\hline Landsat 8 & 2018 & 30 de diciembre & $10: 12: 37$ \\
\hline
\end{tabular}

Fuente: Elaboración propia, adaptado de (USGS, 2018).

Una vez seleccionadas las imágenes satelitales, se procedió a desarrollar la ecuación (1) para calcular la temperatura superficial, a su vez el software ( $\operatorname{rrcGIS\circledR )}$ indico la estadística básica presente en el procesamiento Tabla 3.

Tabla 3. Estadística a partir del procesamiento de las imágenes satelitales

\begin{tabular}{|l|c|c|c|c|}
\hline Días & $\begin{array}{c}4 \text { de enero } \\
2015\end{array}$ & $\begin{array}{c}21 \text { de febrero } \\
2015\end{array}$ & $\begin{array}{c}17 \text { de marzo } \\
2018\end{array}$ & $\begin{array}{c}30 \text { de diciembre } \\
2018\end{array}$ \\
\hline Máxima $\left({ }^{\circ} \mathrm{C}\right)$ & 32,9 & 37,25 & 32,4 & 32,58 \\
\hline Media $\left({ }^{\circ} \mathrm{C}\right)$ & 10,73 & 13,53 & 11,83 & 12,71 \\
\hline Mínima $\left({ }^{\circ} \mathrm{C}\right)$ & $-10,77$ & 8,26 & $-20,75$ & $-4,26$ \\
\hline Desviación estándar & 5,37 & 5,12 & 4,4 & 4,39 \\
\hline
\end{tabular}

Fuente: Elaboración propia. 
Posteriormente, se representó la distribución espacial de las temperaturas de los cuatro días de estudio (Fig. 4). Los cerros orientales al oriente de la imagen, los cuales representan el área rural, muestran una menor temperatura, con rangos entre $8^{\circ} \mathrm{C} \mathrm{a} 12{ }^{\circ} \mathrm{C}$, similar a los datos oficiales de la Corporación autónoma regional de Cundinamarca-Colombia-(CAR) e (IDEAM, 2002); contrastando con el área urbana de hasta $21^{\circ} \mathrm{C}$. Así mismo denotar la presencia marcada de la UHI, en las cuatro fechas analizadas. En cuanto a la UHI analizada, se observan formas geométricas detalladas, así como en los estudios clásicos de (Oke y Maxwell, 1967; Gartland, 2008) principalmente en donde están las estaciones meteorológicas D, F, Q, A y E, coincidiendo localmente con las investigaciones de Gómez y Castañeda para Bogotá en los años 1999, 2005 y 2012 (Gómez y Castañeda, 2013).

Es importante recalcar que, en cuanto a las horas de toma de las imágenes, el sensor realizó las capturas en horas de la mañana, por ende, la superficie terrestre no está del todo caliente siendo el rango de temperatura entre $8{ }^{\circ} \mathrm{C}$ a $20{ }^{\circ} \mathrm{C}$, precisando que hasta ahora está empezando el ciclo diurno de la temperatura. Dicho esto, la isla de calor que se detectó podría llegar a ser de mayor extensión geométrica y magnitud en su escala, llegada la tarde, acorde a lo mencionado por (Weng, 2003; Oke, 1973), en uno de sus estudios realizados en Canadá.

En segundo lugar, se procedió a revisar los datos atípicos hasta 2 desviaciones estándar sin encontrar datos anómalos. Como la mayoría de los datos de las estaciones (Wilks, 2006), suelen tener carencias en las series, se procedió a hallar las correlaciones de Pearson para completar los datos de temperatura, escogiendo las correlaciones positivas más altas por encima de 0.8 para mayor precisión (Tabla 4).

Tabla 4. Correlaciones estadísticas de los datos en las estaciones

\begin{tabular}{|l|c|c|c|c|c|c|c|c|c|c|}
\hline Estaciones & $\begin{array}{c}\text { Carvajal } \\
\text { Sevillana }\end{array}$ & $\begin{array}{c}\text { Centro } \\
\text { Rendimiento }\end{array}$ & Ruaymaral & Kennedy & $\begin{array}{c}\text { Las } \\
\text { Ferias }\end{array}$ & $\begin{array}{c}\text { Puente } \\
\text { Aranda }\end{array}$ & $\begin{array}{c}\text { San } \\
\text { Cristóbal }\end{array}$ & Suba & Tunal & Usaquén \\
\hline Carvajal - Sevillana & 1 & 0,96 & 0,97 & 0,98 & 0,98 & 0,99 & 0,98 & 0,98 & 0,99 & 0,98 \\
\hline $\begin{array}{l}\text { Centro de Alto } \\
\text { Rendimiento }\end{array}$ & 0,96 & 1 & 0,96 & 0,92 & 0,95 & 0,96 & 0,96 & 0,92 & 0,97 & 0,94 \\
\hline Kennedy & 0,98 & 0,92 & 0,95 & 1 & 0,97 & 0,98 & 0,96 & 0,98 & 0,96 & 0,97 \\
\hline Suba & 0,98 & 0,92 & 0,96 & 0,98 & 0,98 & 0,97 & 0,95 & 1 & 0,96 & 0,98 \\
\hline
\end{tabular}

Fuente: Elaboración propia. 


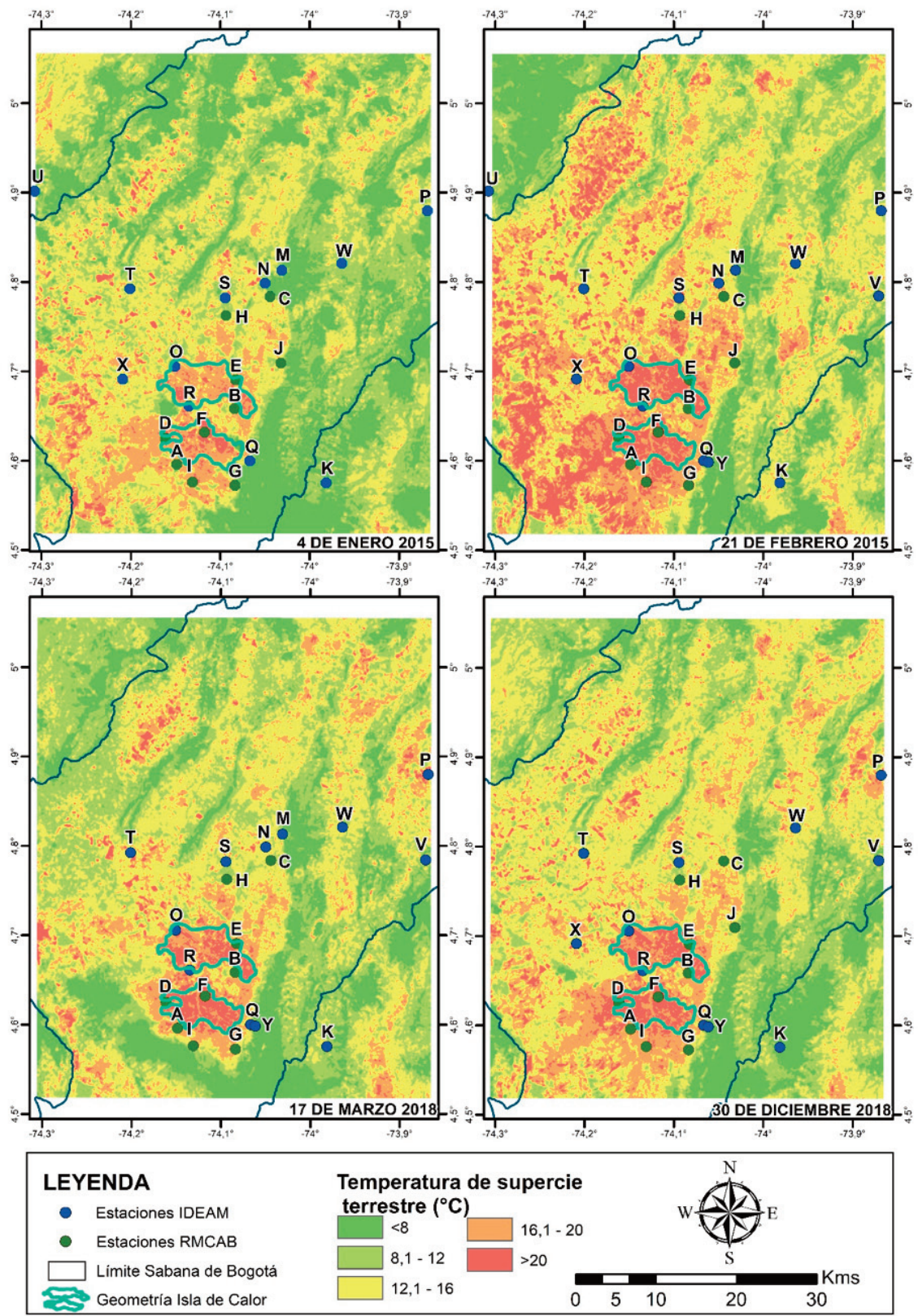

Figura 4. Mapa de la temperatura superficial de imágenes satelitales. Fuente: Elaboración propia. 
Una vez los datos fueron completados se procedió a realizar el análisis estadístico descriptivo, donde se observó el bajo nivel de error y varianza, y los valores medios encontrados ver Tabla 5, coinciden con los de la Organización meteorológica mundial (OMM, 2011).

Tabla 5. Manejo estadístico de las estaciones RMCAB

\begin{tabular}{|l|r|c|r|}
\hline \multicolumn{5}{|c|}{17 de marzo 2018 } \\
\hline Media & 14,32 & Coeficiente de asimetría & $-0,03$ \\
\hline Error típico & 0,36 & Rango & 22,50 \\
\hline Mediana & 14,40 & Mínimo & 3,50 \\
\hline Moda & 13,50 & Máximo & 26,00 \\
\hline Desviación estándar & 5,26 & Suma & 3093,70 \\
\hline Varianza de la muestra & 27,70 & Cuenta & 216,00 \\
\hline Curtosis & $-0,74$ & Nivel de confianza (95,0\%) & 0,71 \\
\hline
\end{tabular}

Fuente: Elaboración propia.

Con los datos analizados se procedió a elaborar el ciclo diurno promedio de la ciudad, para cada día correspondiente a la imagen satelital (Figura 5). De los cuatro días, se observa que en promedio la temperatura más baja se presenta en las horas de la madrugada tipo 5 am hasta 7 am de $8.13^{\circ} \mathrm{C}$, y la más alta se da en promedio entre $2 \mathrm{pm}$ a 4 pm en este caso fue de $21.8^{\circ} \mathrm{C}$, similar al ciclo diurno de un estudio que se realizó en Bogotá en los periodos 1992 a 1998 en el aeropuerto el Dorado (Pabón et al., 1998), donde la temperatura mínima fue de $9.2^{\circ} \mathrm{C}$ así mismo máxima de $18^{\circ} \mathrm{C}$ y a pesar de que son fechas diferentes se mantiene el comportamiento del ciclo con el pasar de los años.

Siguiendo con la parte geoestadística del estudio, en las siguientes tablas se encuentra la validación cruzada de la interpolación del coKriging la cual presenta los diferentes errores, Tabla 6. Siendo estos los que mejor representan la isla de calor en los cuatro modelos de estudio en otras palabras las cuatro fechas, teniendo en cuenta que el valor de la media estandarizada está más cercana a cero es el óptimo para elegir (Martínez, 2012) y tener una predicción cercana al dato original como en el caso de este estudio.

A partir de la representación espacial de la interpolación de las estaciones meteorológicas (Figura 6) se logró identificar en las fechas 4 de enero y 21 de febrero del 2015, las $2 \mathrm{UHI}$; las cuales se forman desde las estaciones A y Q hasta las estaciones $\mathrm{O}$ y J con temperaturas que varían entre $13{ }^{\circ} \mathrm{C}$ y $17^{\circ} \mathrm{C}$; diferente a el rango entre 8 y $14^{\circ} \mathrm{C}$ hacia el Sureste donde están los cerros orientales. Aun así, en la representación espacial del 4 de enero del 2015 la UHI presento un crecimiento hacia el Noroeste con una temperatura 
de entre $13^{\circ} \mathrm{C}$ y $15^{\circ} \mathrm{C}$. Por el contrario, el día 21 de febrero del mismo año, este crecimiento lo presento hacia el Noreste con una temperatura de entre $15^{\circ} \mathrm{C}$ y $16.46^{\circ} \mathrm{C}$. De igual forma, para las fechas 17 de marzo y 30 de diciembre del 2018, se puede decir que el 17 de marzo presenta una UHI de menor geometría en comparación a la que se puede observar en el día 30 de diciembre del 2018 valores menores aproximadamente con una diferencia de temperatura $1^{\circ} \mathrm{C}$. Sin importar el año analizado se puede encontrar una diferencia de temperatura mayor entre la zona urbana a la rural, al oriente de las imágenes, alcanzando diferencias de hasta $8.37^{\circ} \mathrm{C}$ en el 2015 y $8.34^{\circ} \mathrm{C}$ en el 2018.

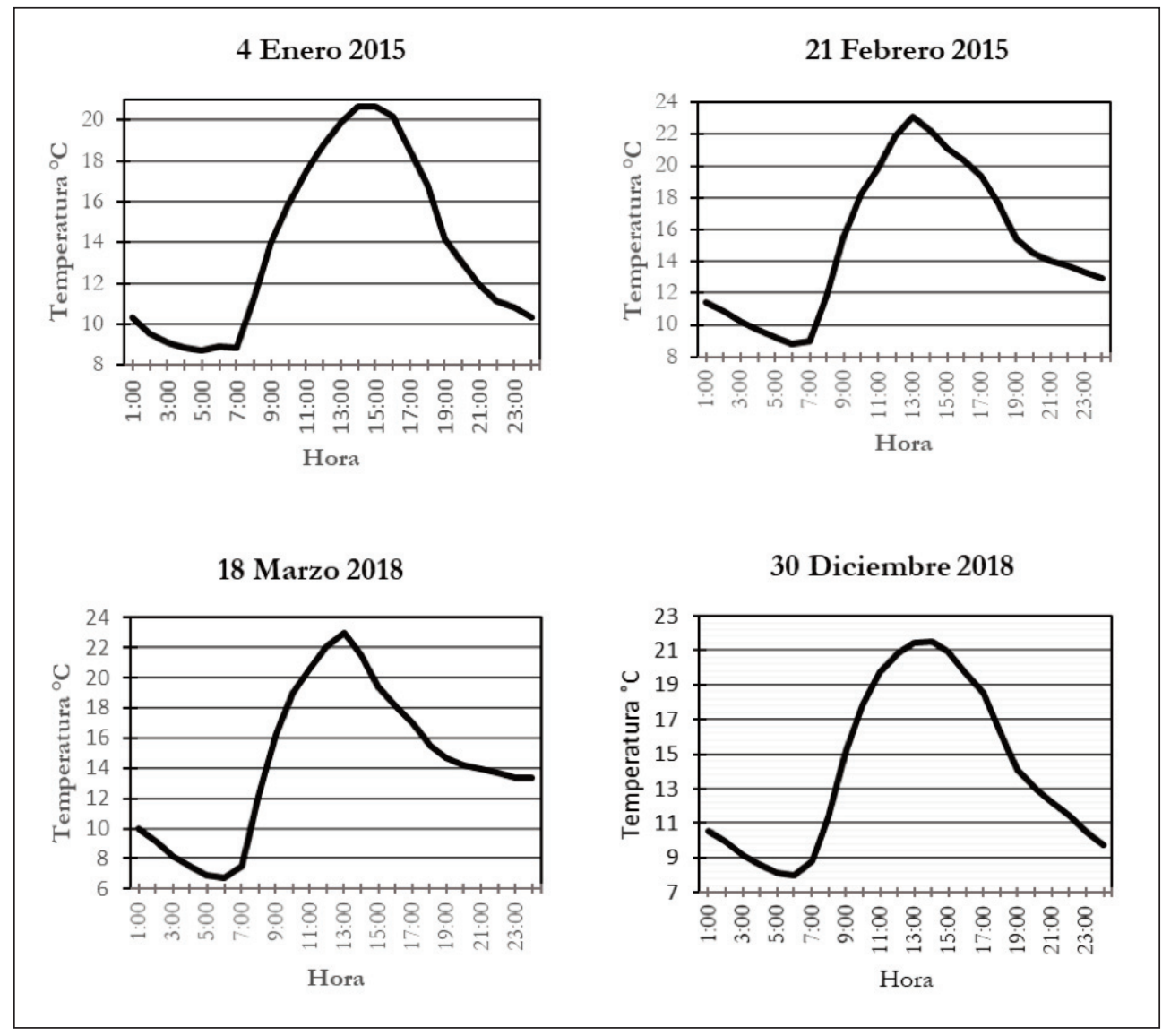

Figura 5. Ciclo diurno de los cuatro días del estudio.

Fuente: Elaboración propia. 
Tabla 6. Validación cruzada

\begin{tabular}{|c|c|}
\hline \multicolumn{2}{|c|}{4 de enero 2015} \\
\hline Muestras & 22 de 22 \\
\hline Media & 0.1792515 \\
\hline Media Cuadrática & 1.761603 \\
\hline Media Estandarizada & 0.08659336 \\
\hline Media Cuadrática Estandarizada & 1.288956 \\
\hline Promedio Error Estándar & 1.235628 \\
\hline \multicolumn{2}{|c|}{17 de marzo 2018} \\
\hline Muestras & 22 de 22 \\
\hline Media & 0.1133094 \\
\hline Media Cuadrática & 1.506174 \\
\hline Media Estandarizada & 0.05464679 \\
\hline Media Cuadrática Estandarizada & 1.192079 \\
\hline Promedio Error Estándar & 1.153818 \\
\hline \multicolumn{2}{|c|}{21 de febrero 2015} \\
\hline Muestras & 24 de 24 \\
\hline Media & 0.1933351 \\
\hline Media Cuadrática & 1.809566 \\
\hline Media Estandarizada & 0.07673536 \\
\hline Media Cuadrática Estandarizada & 1.231041 \\
\hline Promedio Error Estándar & 1.389074 \\
\hline \multicolumn{2}{|c|}{30 diciembre 2018} \\
\hline Muestras & 22 de 22 \\
\hline Media & 0.1530745 \\
\hline Media Cuadrática & 1.760637 \\
\hline Media Estandarizada & 0.04729657 \\
\hline Media Cuadrática Estandarizada & 1.081792 \\
\hline Promedio Error Estándar & 1.586463 \\
\hline
\end{tabular}

Fuente: Elaboración propia. 


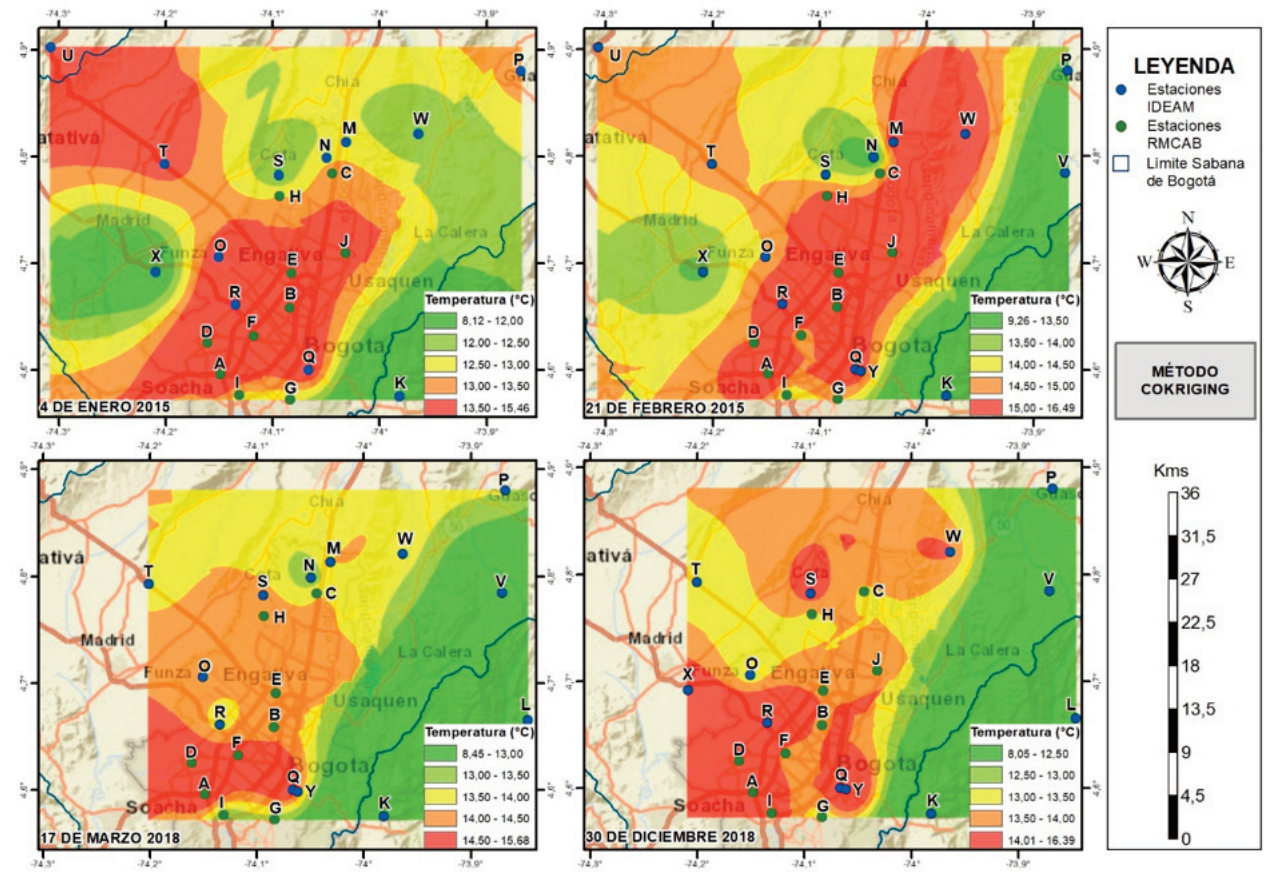

Figura 6. Mapa de temperatura superficial para identificar Islas de calor, a partir de estaciones meteorológicas.

Fuente: Elaboración propia.

En relación con lo anterior, al integrar los métodos de análisis, se encuentra que Kennedy (Figura 7) es uno de los epicentros de las islas de calor tanto en los resultados de las imágenes satelitales como en las estaciones meteorológicas superficiales. Este hallazgo coincide con los resultados presentados por (Figueroa y Fiquitiva, 2017), que encontraron formación de las islas en solo esta localidad, lo cual responde a que este sector tiene características de una gran concentración poblacional que también es mencionado por (Jimémez y López, 2013), y que concuerdan que debido a este fenómeno de la densidad poblacional la localidad de Kennedy es un foco que favorece el crecimiento de la UHI en Bogotá.

Después de obtener los resultados con las imágenes satelitales y estaciones meteorológicas se pudo denotar que, entre los dos mapas, la geometría de las islas es levemente similar teniendo en cuenta que hay muchos factores y variables influyendo en la toma de los datos se pude ver que la isla de calor presente en el centro del mapa es geométricamente. 

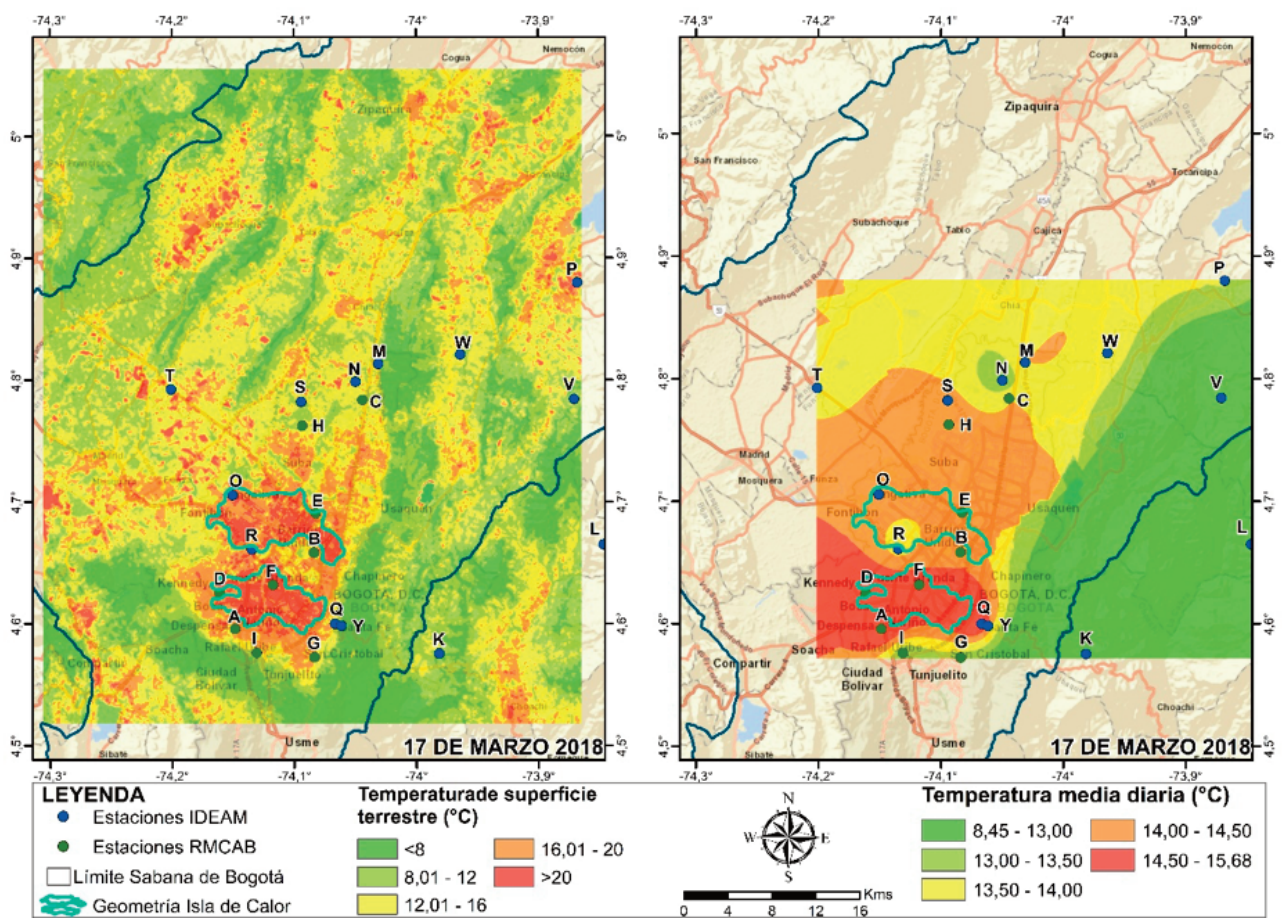

Figura 7. Comparativo entre la imagen satelital y las estaciones meteorológicas 17 de marzo 2018.

Fuente: Elaboración propia.

Por otro lado, no todas las fechas mostraron una similitud geométrica, como se puede ver en la (Figura 8). Las fechas en las que no cumple esta similitud geométrica es debido a que las imágenes satelitales toman los datos en un instante especifico, es decir, a una hora determinada. Por otro lado, se debe tener en cuenta que la manera en la que el satélite capta la imagen lo hace desde una altura considerable, teniendo en este caso la atmosfera que interfiere y puede presentar errores en los datos, en comparación las estaciones meteorológicas pueden tomar datos horarios y así generar el promedio del día o tener datos horarios como es el caso de RMCAB. Esto puede explicar que la geometría de las islas en el caso de la imagen satelital sea heterogénea con el resultado de la estación meteorológica (Pérez et al., 2003), o viéndolo también como un punto en el píxel de la imagen satelital, siendo necesario usar métodos de interpolación para poder obtener una malla más amplia de temperatura. 


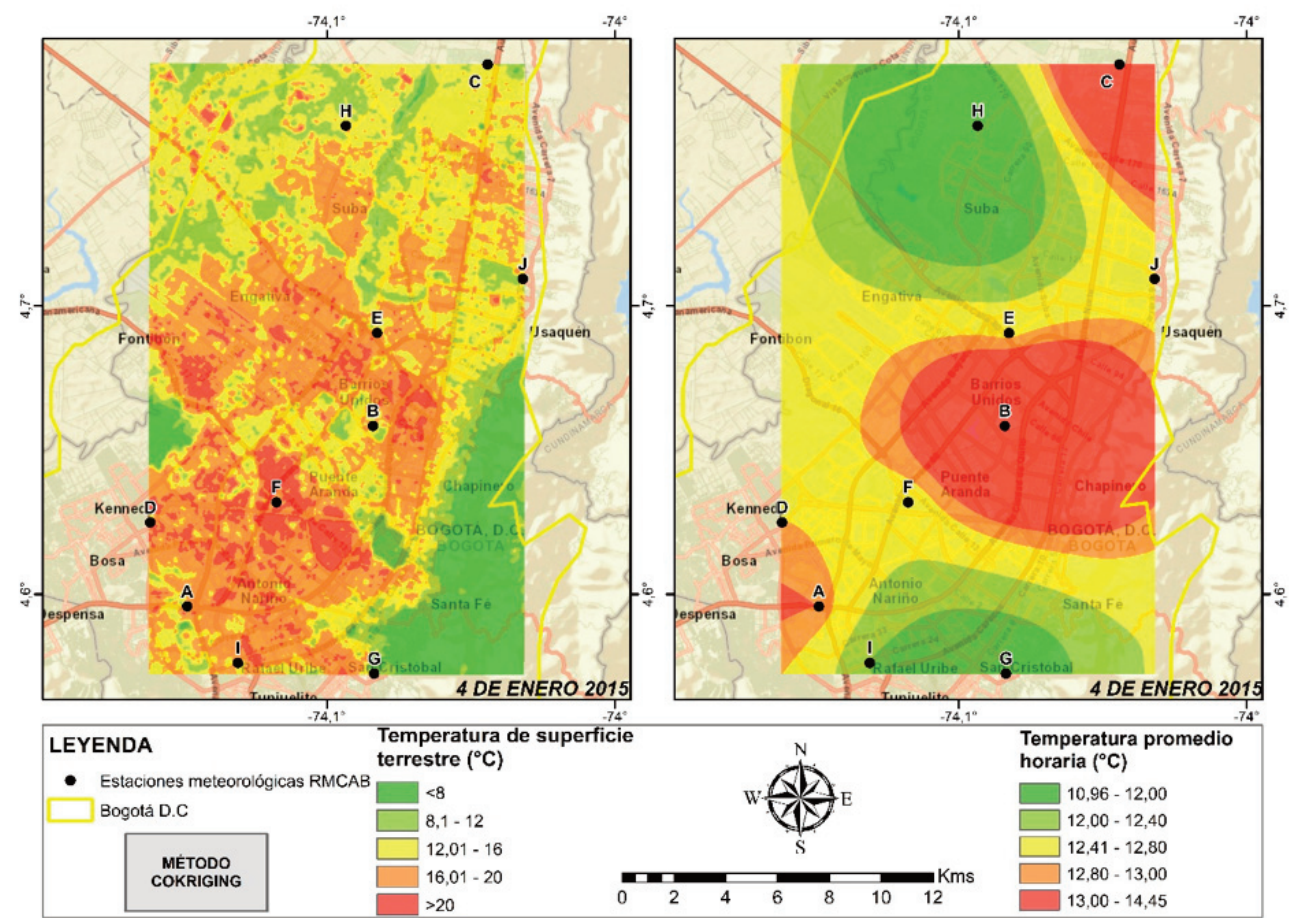

Figura 8. Comparativo entre la imagen satelital y las estaciones meteorológicas 4 de enero 2015.

Fuente: Elaboración propia.

Por último, se tomaron las temperaturas que registran las estaciones meteorológicas y se compararon con las temperaturas de las imágenes satelitales en los 4 días del estudio. Esta comparación de temperaturas se realizó en dos casos: el primero, es la diferencia de temperatura promedio horaria de solo las estaciones de RMCAB contra las imágenes satelitales para los días 4 de enero del 2015 y 17 de marzo del 2018; y el segundo es la diferencia de temperatura promedio diaria entre las estaciones meteorológicas de RMCAB e IDEAM y las imágenes satelitales para los cuatro días.

En el primer caso la menor diferencia fue de $0.2^{\circ} \mathrm{C}$ el 4 de enero del 2015 y la mayor fue de $5.12{ }^{\circ} \mathrm{C}$ presentada el mismo día, como se evidencia en la Tabla 7. Siendo así, que esta diferencia entre las estaciones superficiales y las imágenes satelitales se pueden evidenciar en las zonas mayormente urbanizadas respecto a las de mayor vegetación, en especial en la comparación de los datos superficiales horarios, de manera que esto se puede ver en las estaciones A, D, E, F, H e I, alcanzando valores de hasta $8.27^{\circ} \mathrm{C}$ y las de menor diferencia en las zonas mayor vegetación como en las estaciones $\mathrm{B}, \mathrm{C}, \mathrm{G}$ y J, donde la el mínimo valor de diferencia es de $0.2^{\circ} \mathrm{C}$. 
Tabla 7. Diferencias de temperaturas entre estaciones meteorológicas RMCAB e imágenes satelitales

\begin{tabular}{|l|c|c|c|c|c|c|}
\hline & \multicolumn{3}{|c|}{ 4 de enero 2015 } & \multicolumn{2}{c|}{17 de marzo 2018 } \\
\hline \multirow{2}{*}{$\begin{array}{l}\text { Estación } \\
\text { Meteorológica }\end{array}$} & $\begin{array}{c}\text { TEMp. Estación } \\
\text { Meteorológica }\end{array}$ & $\begin{array}{c}\text { Imagen } \\
\text { Satelital } \\
\text { Estación } \\
\text { Meteorológica }\end{array}$ & $\begin{array}{c}\text { TEMp } \\
\text { Imagen } \\
\text { Satelital }\end{array}$ & Diferencia \\
\hline Carvajal & 13,3 & 18,42 & $-5,12$ & 15,75 & 19,74 & $-3,99$ \\
\hline $\begin{array}{l}\text { Centro de alto } \\
\text { rendimiento }\end{array}$ & 14,75 & 16,3 & $-1,55$ & 15,05 & 14,36 & 0,69 \\
\hline Fontibón & - & - & 0 & - & - & 0 \\
\hline Guaymaral & 15 & 14,63 & 0,37 & 14,05 & 13,29 & 0,76 \\
\hline Kennedy & 12,8 & 17,7 & $-4,9$ & 14,55 & 18,65 & $-4,1$ \\
\hline Las Ferias & 12,5 & 15,73 & $-3,23$ & 14,95 & 16,13 & $-1,18$ \\
\hline Puente Aranda & 12,35 & 15,94 & $-3,59$ & 14,65 & 19,01 & $-4,36$ \\
\hline San Cristóbal & 11,3 & 12,3 & -1 & 13,35 & 14,3 & $-0,95$ \\
\hline Suba & 10,45 & 15,03 & $-4,58$ & 11,3 & 13,99 & $-2,69$ \\
\hline Tunal & 11,75 & 15,75 & -4 & 14,2 & 11 & 3,2 \\
\hline Usaquén & 12,7 & 12,9 & $-0,2$ & - & - & 0 \\
\hline
\end{tabular}

En el segundo caso las diferencias de temperatura se detallan en el Anexo 1 y se encuentra que la menor diferencia entre la temperatura de las estaciones meteorológicas y las imágenes satelitales fue de $0.05^{\circ} \mathrm{C}$ presentada el día 30 de diciembre del 2018 en la estación S, mientras que la mayor fue de $9.45^{\circ} \mathrm{C}$ y ocurrió el mismo día en la estación Y, estación ubicada en los cerros orientales.

Las diferencias de temperaturas que se presentan entre las imágenes satelitales y estaciones meteorológicas se deben a que los dos métodos cuentan con unas mallas con densidades diferentes de datos, lo cual las estaciones tienen una mayor cantidad de datos pero con menor precisión que los que aportan las estaciones meteorológicas, aun así las estaciones meteorológicas cuentan con menor datos lo que requiere de un modelo de interpolación en este caso coKriging, las diferencias de estas temperaturas están sujetos a que los dos métodos tienen diferentes metodologías para crear los mapas de temperatura (Hachem, Duguay y Allard, 2012). 


\section{Conclusiones}

En esta investigación se pudo determinar los niveles de temperatura (LST) de las imágenes satelitales a partir de las bandas ópticas 4 y 5 como de la banda térmica 10 del satélite Polar Landsat 8, haciendo posible identificar islas de calor urbano en la sabana de Bogotá con imágenes satelitales, delimitando la geometría por la diferencia de temperatura que se presentó.

Al momento de comparar los dos métodos se encontró que, en contraste a las estaciones meteorológicas, se debe tener en cuenta que la imagen satelital dispone de una cantidad densa de datos (píxel a píxel), que retrata con mejor precisión espacial la heterogeneidad de distribución de los datos. Las estaciones meteorológicas, abarcan un área menor de cobertura, pero la temperatura medida en estas es más precisa que el dato de temperatura de la imagen satelital, esto se debe a que la imagen satelital puede presentar interferencia o errores por las perturbaciones atmosféricas, especialmente en las zonas concéntricas de la ciudad. De manera que la gran diferencia de temperatura es más notoria en las zonas con mayor urbanización en comparación a las de mayor vegetación.

Cuando se realiza el análisis con los datos diarios de la temperatura, la diferencia de temperatura entre las estaciones IDEAM y RMCAB contra las imágenes satelitales, presentan discrepancias notables debido a la manera que cada método emplea en la toma de datos, así encontrando los mayores contrastes que no solo se dan en las zonas urbanas, sino que se dan en 2 estaciones emplazadas sobre los 2.700 m.s.n.m. de altitud, estaciones K e Y. Por lo que claramente el momento o la hora de comparación, son determinantes para una mayor precisión y a medida que se comparan las imágenes con valores superficiales promedios más extensos se observan valores con mayor magnitud de diferencia, por lo que se hace necesario ampliar este tipo de investigaciones.

En cuanto a la geometría es evidente las similitudes y diferencias encontradas en los dos métodos de estudio, que fueron las imágenes satelitales y las estaciones meteorológicas al momento de identificar las islas de calor, de manera que solamente siendo más específicos el 17 de marzo de 2018, se presentó una similitud geométrica entre los dos métodos de la representación espacial de la isla de calor, una posible razón de que esta similitud geométrica no se diera en los cuatro días con los dos métodos, es que cada método utiliza parámetros diferentes para el cálculo de la temperatura superficial así llegando a diferentes representaciones espaciales de las islas de calor.

Este tipo de estudios muestra que las imágenes satelitales pueden tener un alcance en varios campos, y es bueno seguir empleando estas herramientas para estudios de fenómenos o cambios que se presentan en el medio ambiente y no es fácil obtener datos de manera terrestre. 


\section{Anexos}

\section{Anexo 1: Diferencias de temperaturas entre estaciones meteorológicas} (RMCAB - IDEAM) e imágenes satelitales

\begin{tabular}{|c|c|c|c|c|c|c|c|}
\hline \multirow[b]{2}{*}{$\begin{array}{l}\text { Estación } \\
\text { Meteorológica }\end{array}$} & \multirow[b]{2}{*}{ Letra } & \multicolumn{3}{|c|}{4 de enero 2015} & \multicolumn{3}{|c|}{21 de febrero 2015} \\
\hline & & $\begin{array}{c}\text { Temperatura } \\
\text { Estación } \\
\text { Meteorológica }\end{array}$ & $\begin{array}{c}\text { Temperatura } \\
\text { Imagen } \\
\text { Satelital }\end{array}$ & Diferencia & $\begin{array}{c}\text { Temperatura } \\
\text { Estación } \\
\text { Meteorológica }\end{array}$ & $\begin{array}{c}\text { Temperatura } \\
\text { Imagen } \\
\text { Satelital }\end{array}$ & Diferencia \\
\hline Carvajal & $\mathrm{A}$ & 14,99 & 18,3 & $-3,31$ & 16,5 & 20,92 & $-4,42$ \\
\hline $\begin{array}{l}\text { Centro de alto } \\
\text { rendimiento }\end{array}$ & B & 14,47 & 16,32 & $-1,85$ & 15,54 & 16,22 & $-0,68$ \\
\hline Guaymaral & C & 13,44 & 14,65 & $-1,21$ & 14,74 & 16,5 & $-1,76$ \\
\hline Kennedy & $\mathrm{D}$ & 14,98 & 17,7 & $-2,73$ & 14,99 & 18,8 & $-3,81$ \\
\hline Las ferias & $\mathrm{E}$ & 13,73 & 15,76 & $-2,03$ & 15,58 & 19,66 & $-4,09$ \\
\hline Puente Aranda & $\mathrm{F}$ & 13,83 & 15,82 & $-1,99$ & 14,67 & 17,62 & $-2,95$ \\
\hline San Cristóbal & G & 12,5 & 12,3 & 0,2 & 14,56 & 15,83 & $-1,27$ \\
\hline suba & $\mathrm{H}$ & 13,03 & 15,05 & $-2,02$ & 15,43 & 16,68 & $-1,26$ \\
\hline tunal & I & 12,78 & 15,66 & $-2,88$ & 13,93 & 18,71 & $-4,78$ \\
\hline Usaquén & $\mathrm{J}$ & 13,88 & 12,83 & 1,05 & 16 & 15,13 & 0,87 \\
\hline bolsa la & $\mathrm{K}$ & 8,1 & 7,48 & 0,62 & 9,15 & 13,46 & $-4,31$ \\
\hline col miguel a caro & M & 12,65 & 11,19 & 1,46 & 15,7 & 13,02 & 2,68 \\
\hline $\mathrm{c}$ univ agrop udca & $\mathrm{N}$ & 12,75 & 11,19 & 1,56 & 12,3 & 16,76 & $-4,46$ \\
\hline Eldorado Catam & $\mathrm{O}$ & 14,1 & 14,81 & $-0,71$ & 14,57 & 18,02 & $-3,45$ \\
\hline Guasca & $\mathrm{P}$ & 13,45 & 10,5 & 2,95 & 13,25 & 13,79 & $-0,54$ \\
\hline Idean Bogotá & Q & 14,3 & 11,19 & 3,11 & 16,02 & 12,92 & 3,1 \\
\hline Inem Kennedy & $\mathrm{R}$ & 15,47 & 16,18 & $-0,71$ & 16 & 18,16 & $-2,16$ \\
\hline Nueva Generación & S & 11,9 & 15,51 & $-3,61$ & 14,06 & 16,46 & $-2,4$ \\
\hline Providencia granja & $\mathrm{T}$ & 13,95 & 15,01 & $-1,06$ & 14,8 & 17,45 & $-2,65$ \\
\hline Santa cruz de siecha & $\mathrm{V}$ & - & - & - & 11,2 & 10,48 & 0,72 \\
\hline Suasuque & $\mathrm{W}$ & 11,93 & 11,65 & 0,28 & 16,05 & 14,89 & 1,16 \\
\hline Tibaitata & $\mathrm{X}$ & 10,75 & 9,36 & 1,39 & 13,3 & 17,43 & $-4,13$ \\
\hline Venado oro vivero & $\mathrm{Y}$ & - & - & - & 15,3 & 7,38 & 7,92 \\
\hline
\end{tabular}




\begin{tabular}{|c|c|c|c|c|c|c|c|}
\hline \multirow[b]{2}{*}{$\begin{array}{l}\text { Estación } \\
\text { Meteorológica }\end{array}$} & \multirow[b]{2}{*}{ Letra } & \multicolumn{3}{|c|}{17 de marzo 2018} & \multicolumn{3}{|c|}{30 de diciembre 2018} \\
\hline & & $\begin{array}{c}\text { Temperatura } \\
\text { Estación } \\
\text { Meteorológica }\end{array}$ & $\begin{array}{c}\text { Temperatura } \\
\text { Imagen } \\
\text { Satelital }\end{array}$ & Diferencia & $\begin{array}{c}\text { Temperatura } \\
\text { Estación } \\
\text { Meteorológica }\end{array}$ & $\begin{array}{c}\text { Temperatura } \\
\text { Imagen } \\
\text { Satelital }\end{array}$ & Diferencia \\
\hline Carvajal & A & 15,7 & 19,71 & $-4,01$ & 15,27 & 20,47 & $-5,2$ \\
\hline $\begin{array}{l}\text { Centro de alto } \\
\text { rendimiento }\end{array}$ & B & 14,23 & 14,41 & $-0,18$ & 13,87 & 16,08 & $-2,21$ \\
\hline Guaymaral & $\mathrm{C}$ & 13,96 & 13,33 & 0,63 & 13,4 & 15,19 & $-1,79$ \\
\hline kennedy & $\mathrm{D}$ & 15,34 & 18,68 & $-3,34$ & 15,25 & 18,65 & $-3,4$ \\
\hline Las ferias & $\mathrm{E}$ & 14,26 & 16,17 & $-1,91$ & 13,95 & 18,67 & $-4,72$ \\
\hline Puente Aranda & $\mathrm{F}$ & 14,93 & 18,99 & $-4,06$ & 13,6 & 20,26 & $-6,66$ \\
\hline San cristobal & G & 13,16 & 14,35 & $-1,19$ & 12,93 & 15,11 & $-2,18$ \\
\hline Suba & $\mathrm{H}$ & 14,38 & 14,03 & 0,35 & 13,36 & 15,8 & $-2,44$ \\
\hline Tunal & I & 12,95 & 11,02 & 1,93 & 14,74 & 17,86 & $-3,12$ \\
\hline Usaquen & $\mathrm{J}$ & - & - & - & 13,74 & 13,26 & 0,48 \\
\hline Bolsa la & $\mathrm{K}$ & 8,45 & 11,23 & $-2,78$ & 8,05 & 5,07 & 2,98 \\
\hline Bosque Intervenido & $\mathrm{L}$ & 12,29 & - & - & 10,63 & - & - \\
\hline col miguel a caro & M & 14 & 12,58 & 1,42 & - & - & - \\
\hline c univ agrop udca & $\mathrm{N}$ & 12,95 & 14,71 & $-1,76$ & - & - & - \\
\hline Eldorado Catam & $\mathrm{O}$ & 14,28 & 18,24 & $-3,96$ & 13,08 & 17,76 & $-4,68$ \\
\hline Guasca & $\mathrm{P}$ & 13,6 & 21,63 & $-8,03$ & 10,45 & 18,59 & $-8,14$ \\
\hline Ideam Bogotá & Q & 15,46 & 11,97 & 3,49 & 14,63 & 11,59 & 3,04 \\
\hline Inem kennedy & $\mathrm{R}$ & 13,73 & 19 & $-5,27$ & 16,33 & 17,85 & $-1,52$ \\
\hline Nueva Generación & S & 14,25 & 15,06 & $-0,81$ & 14,4 & 14,45 & $-0,05$ \\
\hline Providencia granja & $\mathrm{T}$ & 13,85 & 17,19 & $-3,34$ & 13,1 & 16,49 & $-3,39$ \\
\hline Santa cruz de siecha & $\mathrm{V}$ & 11,07 & 9,88 & 1,19 & 9,33 & 9,51 & $-0,18$ \\
\hline Suasuque & W & 13,86 & 12,17 & 1,69 & 14,13 & 13,27 & 0,86 \\
\hline Tibaitata & $\mathrm{X}$ & - & - & - & 14,75 & 14,44 & 0,31 \\
\hline Venado oro vivero & $\mathrm{Y}$ & 14,2 & 7,01 & 7,19 & 16,4 & 6,95 & 9,45 \\
\hline
\end{tabular}




\section{Bibliografía}

Alcaldia de Bogotá (2016). Primer Reporte técnico de indicadores de espacio público. Bogotá. Recuperado de http://observatorio.dadep.gov.co/sites/default/files/primerreporteindicadores.pdf

Ariza, A. (2013). Productos LDCM - Landsat 8. Bogotá: IGAC. DOI: https://doi.org/10.13140/ rg.2.2.21308.44167

Arnfield, A.J. (2003). Two decades of urban climate research: a review of turbulence, exchanges of energy and water, and the urban heat island. International Journal of Climatology, 23(1), pp. 1-26. DOI: https://doi.org/10.1002/joc.859

Avdan, U. y Jovanovska, G. (2015). Algorithm for Automated Mapping of Land Surface Temperature Using Landsat 8 Satellite Data. Journal of Sensors, 2016 (1480307), pp. 1-8. DOI: https:// doi.org/10.1155/2016/1480307

Chandler, T.J. (1962). London's Urban Climate. The Geographical Journal, 128 (3), pp. $279-298$. DOI: $10.2307 / 1794042$

Chandler, T.J. (1964). City growth and urban climates. Weather, 19 (6), pp. 170-171. DOI: https:// doi.org/10.1002/j.1477-8696.1964.tb02116.x

Davis, D.L. (2003). A Look Back at the London Smog of 1952 and the Half Century Since. Environmental Health Perspectives, 110( 12), pp. 110-734. DOI: 10.1289/ehp.110-a734

Estoque, R.C., Murayama, Y. y Myint, S.W. (2017). Effects of landscape composition and pattern on land surface temperature: An urban heat island study in the megacities of Southeast Asia. Science of the Total Environment, 577, pp. 349-359. DOI: https://doi.org/10.1016/j.scitotenv. 2016.10.195

Figueroa, T.Z. y Fiquitiva, P.A. (2017). Análisis espacio-temporal de variables que inciden en la generación de isla de calor urbana en la localidad de kennedy. Recuperado de https://repository.usta.edu.co/bitstream/handle/11634/9215/MenesesTanya2017.pdf?sequence=1

Gago, E.J., Roldan, J., Pacheco, R. y Ordóñez, J. (2013). The city and urban heat islands: A review of strategies to mitigate adverse effects. Renewable and Sustainable Energy Reviews, 25 , pp. 749-758. DOI: https://doi.org/10.1016/j.rser.2013.05.057

García, F.M. (2004). Aplicación de la geoestadística en las ciencias ambientales. Ecosistemas, 13 (1), pp. 78-86. Recuperado de http://hdl.handle.net/10045/8813

Garnett, A. (1967). Some Climatological Problems in Urban Geography with Reference to Air Pollution Presidential Address. The Royal Geographical Society, 42, pp. 21-43. DOI: 10.2307/621370

Gartland, L. (2008). Heat Islands: Understanding and Mitigating Heat in Urban Areas. USA: Earthscan from routledge. Recuperado de https://books.google.com.co/books?hl=esylr=yid=oGOsBwAAQBAJyoi=fndypg=PR3ydq=Heat+Islands:+Understanding + and + Mitigating + Heat+in+Urban+Areasyots=f6HlloQptsysig=HTUrqZyOLr1ch-orxiLhkEf 5 X5Q\#v=onepageyq=Heat $\% 20$ Islan ds $\% 3 \mathrm{~A} \% 20$ Understanding\%20and\%20Mitigating $\% 20 \mathrm{H}$

Gómez, L.V. y Castañeda, C.C. (2013). Estudio del Crecimiento Urbano con respecto al Efecto Isla de Calor para establecer Lineamientos de Gestión Energético Ambiental en Bogotá. Eleventh LACCEI Latin American and Caribbean Conference for Engineering and Technology (LACCEI'2013), 11, pp. 1-10. Recuperado de http://www.laccei.org/LACCEI2013-Cancun/RefereedPapers/RP147.pdf 
Hachem, S., Duguay, C.R., y Allard., M. (2012). Comparison of MODIS-derived land surface temperatures with ground surface and air temperature measurements in continuous permafrost terrain. Copernicus Publications on behalf of the European Geosciences Union, pp. 51-69. DOI: https://doi.org/10.5194/tc-6-51-2012

Haro, A.G. (2017). Diseño del espacio público e isla de calor urbana: Una aproximación desde el estudio de las características microclimáticas de las ramblas de Barcelona. Barcelona: ETSAB. Recuperado de https://docplayer.es/56600319-Diseno-del-espacio-publico-e-isla-de-calor-urbana.html

Henao, R.G. (2015). Introducción a la Geoestadistica. Bogotá: Universidad nacional de Colombia.

Howard, L. (1833). The Climate of London. London: International Association for Urban Climate (IAUC). Recuperado de https://www.urban-climate.org/documents/LukeHoward_Climateof-London-V1.pdf

IDEAM (2002). Estudio de la caracterización clímatica de Bogotá y cuenca alta del río Tunjuelo. Bogotá: IDEAM. Recuperado de http://www.ideam.gov.co/documents/21021/21135/CARACTERIZACION+CLIMATICA+BOGOTA.pdf/d7e42ed8-a6ef-4a62-b38f-f36f58db29aa

IDEAM (2018). Instituto de Hidrología, Meteorología y Estudios Ambientales - IDEAM. Recuperado de http://www.ideam.gov.co/geoportal

Imhoff, L.M., Zhang, P., Wolfe, R.E. y Lahouari, B. (2010). Remote sensing of the urban heat island effect across biomes in the continental USA. Remote Sensing of Environment, 114 (3), pp. 504513. DOI: https://doi.org/10.1016/j.rse.2009.10.008

Jauregui, E. y Romales, E. (1996). Urban effects on convective precipitation in Mexico city. Atmospheric Environment, 30 (20), pp. 3383-3389. DOI: https://doi.org/10.1016/1352-2310(96)00041-6

Jimémez, I.C. y López, M.R. (2013). Repositorio Institucional Universidad Piloto de Colombia. Recuperado de http://repository.unipiloto.edu.co/bitstream/handle/20.500.12277/3175/000 00845.pdf?sequence $=1$

Pabón, J.D., Zea, J., León, G., Hurtado, G., González, O. y Montealegre, J. (2001). La atmósfera, el tiempo y el clima. En: Leyva, P. (Eds.), El medio ambiente en Colombia (pp. 34-91). Bogotá: IDEAM.

Lo, C.P., Quattrochi, D.A. y Luvall, J.C. (1997). Application of high-resolution thermal infrared remote sensing and GIS to assess the urban heat island effect, 18 (2), pp. 287-304. DOI: https://doi.org/10.1080/014311697219079

Matson, M., Mcclain, E.P., McGinnis, D.F. y Pritchard, J.A. (1978). Satellite Detection of Urban Heat Islands. Monthly Weather Review, 106 (12), pp. 1725-1734. DOI: https://doi.org/10.1175/15200493(1978)106<1725:SDOUHI >2.0.CO;2

Morris, C.J., Simmonds, I. y Plummer, N. (2001). Quantification of the Influences of Wind and Cloud on the Nocturnal Urban Heat Island of a Large City. Journal of Applied Meteorology, 40 (2), pp. 169-182. DOI: https://doi.org/10.1175/1520-0450(2001)040<0169:QOTIOW>2.0.CO;2

Muños, K. y Naranjo, L. (2015). Comparación estadística actualizada de zonas verdes públicas de Bogotá distrito capital con algunas de las capitales suramericanas. Recuperado de Repositorio Universidad Distrital: http://repository.udistrital.edu.co/bitstream/11349/5000/1/NaranjoOrjuelaLauraCatherin2015.pdf 
Narváez, I. y Ruiz, M. (2013). Identificación y propuesta de estrategias de mitigación del efecto de isla de calor para una localidad del distrito capital. Recuperado el 20 de 6 de 2018 de http://polux.unipiloto.edu.co:8080/00000845.pdf

Oke, T. (1976). The distinction between canopy and boundary-layer urban heat islands. Atmosphere, pp. 268-277. DOI: https://doi.org/10.1080/00046973.1976.9648422

Oke, T.R. (1973). City size and the urban heat island. Atmospheric Environment Pergamo, 7, pp. 769-779. DOI: https://doi.org/10.1016/0004-6981(73)90140-6

Oke, T.R. (1982). The energetic basis of urban heat island. Quarterly Journal of the Royal Meteorological Society, 108 (455), pp. 1-24. DOI: https://doi.org/10.1002/qj.49710845502

Oke, T.R., y Maxwell, G.B. (1967). Urban heat island dynamics in Montreal and Vancouver. Atmospheric Environment, 9 (2), pp. 91-200. DOI: https://doi.org/10.1016/0004-6981(75)90067-0

Oke, T., Johnson, G. y Steyn, D. (1991). Simulation of surface urban heat islands under 'ideal' conditions at night. Boundary-Layer Meteorology, 56, pp. 339-358. DOI: https://doi.org/10.1007/ BF00119211

Organización Metereológica Mundial (2011). Guía de prácticas climatológicas. Bogotá: ORG11.

Osorio, A.M. (2017). Islas de calor en el área urbana del Valle de Aburrá. Recuperado el 16 de 5 de 2018 de http://bdigital.unal.edu.co/57837/1/1039453046.2017.pdf

Pabón, J.D., Pulido, S.I., Jaramillo, O. y Chaparro, J. (1998). Análisis preliminar de la isla de calor en la Sabana de Bogotá. Cuadernos de Geografía: Revista Colombiana de Geografía, 7 (1-2), pp. 87-93. Recuperado de https://revistas.unal.edu.co/index.php/rcg/article/view/70835

Perez, A. (2000). Estructura ecológica principal de la Sabana de Bogotá. Bogotá: Sociedad geográfica de Colombia academia de ciencias geográficas. Recuperado de https://www.sogeocol.edu.co/documentos/est_eco.pdf

Pérez, C.A. (2014). Islas de calor urbano en Tampico, México. Impacto del microclima a la calidad del hábitat. Nova Scientia, 7 (13), pp. 495-515. DOI: https://doi.org/10.21640/ns.v7i13.41

Pérez, M.G., García, M.P. y Guerra, A.Z. (2003). Análisis del clima urbano a partir de imágenes de satélite en el centro peninsular español. Anales de Geografia de la Universidad Complutense, 23, pp. 187-206. Recuperado de https://dialnet.unirioja.es/servlet/articulo?codigo=976115

Rizwan, M., Dennis, Y.C. y Liu, C. (2008). A review on the generation, determination and mitigation of Urban Heat Island. Journal of Environmental Sciences, 20 (1), pp. 120-128. DOI: https://doi.org/10.1016/S1001-0742(08)60019-4

RMCAB (2018). Red de monitoreo de calidad del aire de Bogotá. Recuperado de http://ambientebogota.gov.co/red-de-calidad-del-aire

Rodríguez, C., Gallardo, M.Á., Pozo, M.T. y Gutiérrez, J. (2006). Iniciación al análisis de datos cuantitativos en educación. Teoría y práctica mediante spss del análisis descriptivo básico. España: Editorial GEU.

Senanayake, I., Welivitiya, W. y Nadeeka, P. (2013). Remote sensing based analysis of urban heat islands with vegetation cover in Colombo city, Sri Lanka using Landsat-7 ETM+ data. Urban Climate, 5, pp. 19-35. DOI: https://doi.org/10.1016/j.uclim.2013.07.004 
Soto, E. (2019). Estimación de la isla de calor urbana en Medellín, Colombia. Rev. Int. Contam. Ambie, 35 (2), pp. 421-434. DOI: http://dx.doi.org/10.20937/RICA.2019.35.02.13

Taha, H. (1997). Urban climates and heat islands: albedo, evapotranspiration, and anthropogenic heat. Energy and Buildings, 25 (2), pp. 99-103. DOI: https://doi.org/10.1016/S0378-7788(96) 00999-1

Thomas, G., Sherin, A.P., Ansar, S. y Zachariah, E.J. (2014). Analysis of Urban Heat Island in Kochi, India, Using a Modified Local Climate Zone Classification. Procedia Environmental Sciences, 21, pp. 3-13. DOI: https://doi.org/10.1016/j.proenv.2014.09.002

USGS (2018). Earth Explorer. Recuperado el 14 de Octubre de 2019 de https://earthexplorer.usgs.gov/

USGS (2018). United States Geological Survey. Recuperado el 2018 de https://www.usgs.gov/

USGS (2018). USGS EROS Archive - Landsat Archives - Landsat 8 OLI (Operational Land Imager) and TIRS (Thermal Infrared Sensor) Level-1 Data Products. Recuperado el 14 de Octubre de 2019 de https://www.usgs.gov/centers/eros/science/usgs-eros-archive-landsat-archives-landsat-8-oli-operational-land-imager-and?qt-science_center_objects=0\#qt-science_center_objects

Vide, J.M., Sarricolea, P. y Moreno, M.C. (2015). On the definition of urban heat island intensity. Frontiers in Earth Science, 3, pp. 1-2. DOI: https://doi.org/10.3389/feart.2015.00024

Weng, Q. (2003). Fractal Analysis of Satellite-Detected Urban Heat Island Effect. Photogrammetric Engineering y Remote Sensing, 69 (5), pp. 555-566. DOI: doi:https://doi.org/10.14358/PERS.69.5.555

Wilks, D. (2006). Statistical methods in the atmospheric sciences. London: Elseiver.

Xiao, L., Hong, M., Ping, X. y Zhi, Y. (2006). Remote sensing image-based analysis of the relationship between urban heat island and land use/cover changes. Remote Sensing of Environment, 104(2), pp. 133-146. DOI: https://doi.org/10.1016/j.rse.2005.11.016

Zhou, B., Rybski, D. y Kropp, J.P. (2017). The role of city size and urban form in the surface urban heat island. Nature, pp. 412-420. doi:https://doi.org/10.1038/s41598-017-04242-2 